\title{
História e Ficção na França Antártica
}

Ana Arruda CALLADO*

Resumo: A dificuldade de separar história e ficção. Lembrando o seminário, realizado neste mesmo Museu Histórico Nacional, sobre "A história é outra estória". A chuva ácida de Léry e o animal que vive de vento, de Thevet. A própria teoria de bom selvagem como prova da visão fantasiosa dos cronistas da França Antártica. As belas biografias ficcionais de Serge Elmalan e Chermont de Britto e a cuidadosa biografia não/ficcional de Vasco Mariz. Quando o que importa é a versão e não o fato.

Palavras-Chave: França Antártica; Colonização Francesa; História e Ficção.

Há cerca de cinco anos, foi realizado um seminário neste mesmo Museu Histórico Nacional com o tema "A história é outra estória". À mesa, o cineasta Sílvio Tendler, especialista em filmes documentários históricos, os escritores Marina Colasanti e José Roberto Torero, o qual havia lançado há pouco e com muito sucesso seu $O$ Chalaça, e eu. Falamos todos mais ou menos sobre a mesma coisa: a dificuldade que há em separar, delimitar história e ficção, embora na platéia alguns historiadores ficassem um tanto aborrecidos pelo fato de não darmos grande crédito aos documentos - Quem os elaborou e a serviço de quem? Quem os guardou e com quais intenções? Os documentos perdidos, ou propositalmente destruídos, não provariam outra

* Professora Aposentada - Doutora em Comunicação Social - Escola de Comunicação - UFRJ - 22290-240 - Rio de Janeiro - RJ - Brasil. E-mail: aacallado@hotmail.com 
coisa? - foram alguns dos questionamentos. Os maiores aplausos da platéia naquela tarde foram para Torero, especialmente quando respondeu à pergunta: "O que é verdade e o que é ficção em seu livro?"

"O que eu escrevi, o que eu inventei, é tudo verdade, pois fui eu quem escreveu. Agora, os documentos que usei, não sei. Não respondo por eles", disse.

Estamos aqui falando da França Antártica, episódio histórico que deu nascimento a grande quantidade de obras incluídas na historiografia, algumas básicas, e, ao mesmo tempo, boas obras de ficção. As fontes primárias para todas elas são, principalmente, os livros dos cronistas franceses que aqui estiveram com Villegagnon, particularmente Jean de Léry e André Thevet. Devemos considerar Léry e Thevet como historiadores? Isto é, devemos considerar seus relatos parte da História, aquela com $\underline{h}$ e às vezes até com $\mathrm{H}$ maiúsculo?

Vejamos alguns pequenos trechos retirados dos admiráveis livros desses cronistas, A cosmografia universal e História de uma viagem feita à terra do Brasil, também chamada América publicados, respectivamente, em 1575 e 1580. (As citações têm origem nas edições preparadas pela Fundação Darcy Ribeiro e ainda em fase de editoração, não havendo, portanto, paginação definitiva.)

Diz o franciscano Thevet, ao descrever plantas e animais da França Antártica, nome que, aliás, ele assegura ter cunhado:

"Existe ainda uma árvore muito alta, mais que a mencionada anteriormente, e que se encontra em todo o país, e a que os bárbaros chamam de Amahut (trata-se da imbaúba, árvore de cujas folhas e brotos se alimenta, preferencialmente, o bichopreguiça), na qual fica habitualmente um animal tão disforme e quase inacreditável para quem não o tenha visto por sua experiência; chama-na Haût, ou Haüthi, porque são [os nativos] de opinião que se alimenta das folhas da mencionada árvore Amahut. Este animal é do mesmo tamanho de um grande 
macaco que se traz da África, e tem o ventre caído quase até o chão, mesmo de pé. O rosto e a cabeça são quase semelhantes aos de uma criança, e sua carne é tão desagradável para comer como a de um dogue velho, pois é grosseira e sem gosto; acrescente-se a isso que os selvagens da região têm a louca convicção de acreditar que quem a coma, mal conseguiria escapar das mãos de seus inimigos, já que é lento para caminhar, o que dizem de vários outros animais, como já falei antes. Quando esse Haüt é capturado, solta grandes suspiros, exatamente como faria um homem sofrendo de uma grande e excessiva dor; é coberto de pêlos muito claros e de cor cinzenta. Tem apenas três unhas em cada pata, com quatro dedos de comprimento, com a forma das arestas de uma carpa, e com essas garras sobe nas árvores, onde fica muito mais tempo que na terra; a cauda tem apenas um comprimento de três dedos, como podem ver no desenho que aqui aparece tirado do natural. De resto, o Haüt é um caso muito estranho, pois jamais homem vivo poderia dizer que o viu comer qualquer coisa, apesar de os selvagens os terem mantido durante muito tempo (como eles mesmos me contaram) em suas habitações, para ver se comia alguma coisa. No que eu não acreditaria, se não tivesse tido a prova."

Thevet então conta como guardou um bicho-preguiça durante muito tempo e este não comeu coisa alguma. Daí ele ter afirmado no título do capítulo e na legenda do desenho: "o animal que só vive de vento".

O exemplo a seguir que selecionei de Jean de Léry é mais impressionante, porque o que ele afirma foi repetido por outros escritores da época. Ao falar das privações que haviam passado durante a travessia marítima da França ao Rio de Janeiro, informa:

"Havia também as chuvas das vizinhanças do Equador que não só são fétidas como pestilentas; batendo na pele de alguém provocam pústulas e grandes bolhas, chegando mesmo a manchar e estragar as roupas. Além disso, o sol era fortíssimo e grande o sofrimento causado pelo calor e, fora de duas parcas refeições, não tínhamos água doce nem outra bebida em 
quantidade suficiente. Sofríamos assim tão cruelmente a sede que quase cheguei a perder a respiração e a ficar sem fala durante mais de uma hora, donde se compreende que o que mais desejam os marinheiros nessas viagens longas é ver o mar convertido em água doce."

O final deste trecho dá a entender, para mim, que o sol e a sede influíram na descrição que o cronista faz da chuva equatorial.

Temos que levar em conta também que estes dois escritores e homens de conhecimentos científicos bastante respeitáveis na época acusaram-se mutuamente de mentirosos. Não a propósito de chuvas ou animais monstruosos, mas sobre o que de fato se passava entre católicos e calvinistas na colônia francesa. Villegagnon, para um, vilão, para outro, herói, foi o motivo maior da discórdia. Vejamos as palavras empregadas por Léry no prefácio de seu livro:

"Ao verificar, neste ano de 1577, pela literatura da Cosmografia de Thévet, que não somente repetia ele suas mentiras [as do livro Singularidades da França Antártica] e ampliava seus primeiros erros (sem dúvida na esperança de que todos estivéssemos enterrados ou não ousássemos contradizê-lo) mas ainda se valia da oportunidade para caluniar com digressões falsas e injuriosas os ministros e imputar mil crimes aos que, como eu, os acompanharam em 1556 à terra do Brasil para ir ter com Villegagnon, vi-me compelido a dar à luz o relato de nossa viagem."

Mentiroso é como também o autor da Cosmografia, em texto posterior, História de duas viagens, qualifica Jean de Léry.

Ao receber o Prêmio Nobel de Literatura em 1982, o colombiano Gabriel García Márquez falou dos relatos fantasiosos dos primeiros viajantes europeus à América, justificando seu "realismo mágico" como o gênero mais adequado à região. Iniciou com o exemplo do livro navegador florentino Francesco Antonio Pigafetta [nascido em 1491 e morto em 1534], que acompanhou Fernão de Magalhães em sua viagem que 
pretendia realizar a circunavegação do globo terrestre. Pigafetta foi dos poucos sobreviventes da expedição a voltar à Espanha com Juan Sebastián Elcano.

(Aliás, sobre esta trágica viagem de Magalhães há um romance interessantíssimo, Maluco, do uruguaio Napoleon Ponce de Leon, que recebeu o Prêmio Casa de Las Americas, de Havana, em 1989. O livro foi publicado no Brasil em 1992, pela Companhia das Letras, de São Paulo, com tradução de Eric Nepomuceno.)

Pigafetta conta que viu, na América do Sul, entre outras coisas bastante extravagantes, porcos com o umbigo no lombo, pássaros sem patas cujas fêmeas chocavam seus ovos nas costas do macho e um animal com cabeça e orelhas de mula, corpo de camelo, patas de veado e relincho de cavalo.

García Máquez citou ainda, para reforçar sua tese, o fato de Eldorado ter figurado em numerosos mapas, mudando de lugar e de forma segundo a fantasia dos cartógrafos, e a realização, por Álvar Nuñez Cabeza de Vaca, de uma expedição que durante oito anos percorreu o norte do México em busca da Fonte da Eterna Juventude.

Voltando à França Antártica, quero citar um artigo de Monique Augras, doutora pela Universidade de Paris, pesquisadora do CPDOC da Fundação Getúlio Vargas, na revista Estudos Históricos (volume 4, número 7, de 1991). No artigo intitulado "Imaginária França Antártica", Monique faz uma advertência que interessa muito ao tema de nossa mesa:

"Não existe percepção objetiva. Todo registro perceptivo supõe uma seleção de elementos significativos para o sujeito, a partir da estruturação da interação entre o organismo e seu meio. Nesse processo, intervêm aspectos tanto culturais quanto psicofísiológicos. Aos viajantes, era impossível olhar a nova paisagem da costa brasileira, sem recorrer a um esquema perceptivo/interpretativo já estabelecido. Desejos e expectativas filtravam a sua visão. Em sua bagagem, misturavam-se informações eruditas e populares, tradições cristãs e lendas antigas, alguns versos de Ovídio e páginas de escritores contemporâneos. 
Para o homem do século XVI, conhecer o mundo é decifrar a obra de Deus. Essa nova natureza que se oferece à contemplação dificulta o entendimento. Será preciso isolar elementos que, interpretados em função de sua relativa semelhança com coisas já conhecidas, se transformarão em signos. A paisagem enigmática acabará sendo lida como se fosse uma mensagem." (p. 21)

As referências à pureza e à bondade dos indígenas brasileiros, que deram origem ao mito do "bom selvagem", nos relatos de Thevet e Léry mesclam-se a adjetivos terríveis, principalmente quando condenam a nudez e o canibalismo - hoje posto em dúvida pelos estudiosos, principalmente como hábito generalizado - dos "bárbaros". As índias, principalmente, são alvo da rejeição dos dois cronistas, que ora falam de sua maldade, ora de seu despudor; Thevet utiliza para elas o termo "cadelas". Monique Augras explica:

"À medida que os pensadores europeus se vão desencantando com sua própria sociedade, o suposto 'estado de natureza' passa a ser valorizado. É esta a posição de Montaigne que, ouvindo o relato de um daqueles marinheiros que se fixara 'por 10 ou 12 anos no lugar onde Villegagnon se assentou, e que apelidou de França Antártica', chega à conclusão de que 'nada há que seja bárbaro ou selvagem nessa nação, a não ser que cada qual chama de bárbaro aquilo que não faz parte dos seus costumes'. Desgostoso com as atrocidades perpetradas por católicos e protestantes no decorrer das Guerras de Religião, Montaigne sonha com homens vivendo em estado de inocência original. Como bem observou Todorov (1989), na verdade Montaigne está menos interessado nas reais condições de vida dos tupinambás do que na denúncia das inadequações de sua própria sociedade". ( p. 24)

Enfim, todas essas considerações nos levam a reafirmar que quase sempre vale mais a versão do que o fato.

Os livros de Serge Elmalan, Villegagnon e a utopia tropical, e de Chermont de Britto, Vilegagnon o rei do Brasil são 
romances, pertencem ao reino da ficção; mas são tão ricos de informações quanto Villegagnon e a França Antártica, de Vasco Mariz e Lucien Provencal. E este é de tão saborosa leitura quanto aqueles. Enfim, é muito difícil traçar limite entre história e ficção, mais ainda quando estamos nos referindo à França Antártica.

CALLADO, Ana Arruda. History and Fiction in the French Antarctic. História, v.27, n.1, p.135- 142, 2008.

Abstract: The difficulty of separating history from fiction. Remembering the seminar that took place in this same National History Museum about "The History is Another Story". The acid rain of Lery and the animal that lived off the wind, of Thevet. The theory itself of the good savage as proof of the fanciful vision of the chroniclers of the French Antarctic. The beautiful, fictional biographies of Serge Elmalan and Chermont de Britto, and the careful non-fictional biography of Vasco Mariz. When what mattered was the version and not the fact.

Keywords: French Antarctic; French Colonization; History and Fiction.

Artigo recebido em 03/2008. Aprovado em 07/2008. 
